\title{
Sobre heróis índios, arautos modernos e a performatividade das manchetes: a auralidade de O Guesa, de Sousândrade, ou a epopeia como meio de comunicação
}

\author{
Marco Thomas Bosshard*
}

\section{Resumo}

Este artigo enfoca $O$ Guesa, epopeia do poeta romântico brasileiro Sousândrade. Partindo da metodologia dos Estudos Teatrais e do conceito de 'auralidade', que implica a combinação de um texto escrito com a sua recitação pública diante de um auditório, dá-se atenção especial ao texto da representação épica, de maneira que se analisa a epopeia não como gênero literário, senão como um meio de comunicação que relaciona o poeta com o seu público. O Guesa contém vários elementos - por exemplo, arautos modernos que vociferam a sintaxe característica das manchetes dos jornais do século 19 , bem como o jogo recorrente com a polissemia e a homofonia - que requerem uma encenação performativa do texto épico escrito. Com a interligação da escrita clássica (épica) e modernos recursos literários (do jornalismo) consegue Sousândrade uma reformulação da expressão literária. Isto não se limita apenas ao nível textual, mas a reformulação se reflete na diversidade das fontes e faz aparecer O Guesa em um contexto pan- continental e pan-medial.

Palavras-chave: Jornalismo. Literatura brasileira. Sousândrade. Oralidade e literalidade. Epopeia.

\footnotetext{
* Professor Adjunto de Estudos Culturais Latinoamericanos e Ibéricos, Romanisches Seminar, Ruhr-Universität Bochum, Bochum, Alemanha. Doutor em Filologia Românica pela Albert-Ludwigs-Universität Freiburg i.Br, (Alemanha). É especialista em vanguardas latinoamericanas e publicou as monografias "La reterritorialización de lo humano - Una teoría de las vanguardias americanas" (Pittsburgh, 2012) e "Ästhetik der andinen Avantgarde" (Berlim, 2002).

E-mail: Marco.Bosshard@ruhr-uni-bochum.de
} 


\section{About native heroes, modern heralds and the performativity of headlines: the aurality of $O$ Guesa, by Sousândrade, or epic poetry as a media of communication}

\section{Abstract}

This article analyzes the epic poem O Guesa, written by Brazilian poet Sousândrade. Making use of the methodological frames of Theater Studies and the concept of 'aurality', that implies the combination of a written text with its public reading, the author focusses on the text of epic representation in order to discuss the text not as belonging to the literary genre of epic poems but as a media of communication that relates poet and public. O Guesa contains several elements - i.e. modern heralds who pronounce the caracteristic syntax of $19^{\text {th }}$-century newspaper headlines as well as polysemic and homophonic strategies - that require a performative staging of the written epic text. Intertwining classical (epic) writing and modern literary styles (present in journalism), Sousândrade reformulates the question of literary expression. This is not only limited to the text level, but his reformulation also reflects the diversity of sources the work is based upon, repositioning O Guesa in a pancontinental and panmedial context.

Keywords: Journalism. Brazilian literature. Sousândrade. Orality and literacy. Epic poems.

\section{Sobre héroes indios, heraldos modernos y la performatividad de los titulares: la auralidad de O Guesa, de Sousândrade, o la epopeya como medio de comunicación}

\section{Resumen}

Este artículo enfoca en $O$ Guesa, epopeya del poeta romántico brasileño Sousândrade. Partiendo de la metodología de los Estudios Teatrales y del término de 'auralidad' que implica la combinación de un texto escrito con su recitación pública delante de un auditorio, se presta atención especial al texto de la representación épica, de modo que se analiza la epopeya no como género literario sino como un medio de comunicación que relaciona al poeta con su público. Se hallan en O Guesa varios elementos - por ejemplo, unos heraldos modernos que vociferan la sintaxis característica de los titulares de los periódicos del siglo XIX así como el juego recurrente con la polisemia y la homofonía - que requieren una puesta en escena performativa del texto épico escrito. Con la vinculación de la escritura clásica (épica) con los modernos recursos literarios (del periodismo) Sousândrade consigue reformular la expresión literaria - reformulación que no solamente se limita al nivel textual, sino que se refleja también en la diversidad de las fuentes que ubican $O$ Guesa en un contexto pancontinental y panmedial. Palabras clave: Periodismo. Literatura brasileña. Sousândrade. Oralidad y literalidad. Epopeya. 


\section{Marco teórico e metodológico: auralidade, texto épico e texto da representação}

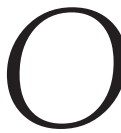

Guesa, epopeia monumental, escrita durante vários decênios sem nunca ter sido terminada, é considerada hoje como um dos textos mais originais e singulares do Romantismo Brasileiro. Além disso, é considerada, graças a sua reivindicação e quase canonização devido aos estudos de Augusto e Haroldo de Campos (1982), Frederick G. Williams (1976) e Luiza Lobo (1986), como uma obra precursora das poéticas radicais do modernismo brasileiro tal como se constituiu nos anos 1920 do século 20. O autor de $\mathrm{O}$ Guesa, Joaquim de Sousa Andrade (1832/33-1902), utiliza uma espécie de pseudônimo, chamando-se Sousândrade, ou seja, mistura seus dois sobrenomes recorrendo, além disso, a uma esdrúxula forma que não respeita a acentuação normal do português. Este fato para mim é notável, pois não é somente uma manifestação do não-conformismo pessoal do escritor, mas se reflete nele também aquele fenômeno que gostaria de abordar no marco deste artigo: o aspecto auditivo e performativo do gênero da epopeia na era moderna, para o qual utilizarei o termo de 'auralidade', que definirei mais adiante.

Publicaram-se nos últimos anos vários estudos dedicados à reavaliação das antigas formas épicas na modernidade, muitos deles dirigidos ou escritos por autores brasileiros (Beissinger et al., 1999; Duarte, 1993; Labarthe, 2004; Neiva, 2009a, 2009b e 2008; Oberhelman et al., 1994; Silva e Ramalho, 2007). Este fato talvez permita supor que uma perspectiva sobre o fenômeno a partir da literatura brasileira contribui para uma melhor compreensão da reemergência do gênero que produz conclusões que são válidas também para as literaturas européias e mundiais que configuraram o nexo fatal entre epopeia e nacionalismo - um nexo corrigido, em parte, por um utópico supranacionalismo americano que começa com Sousândrade e termina, no século 20, com o Canto general, de Neruda.

Assim, as presentes indagações sobre Sousândrade se inscrevem em um projeto mais amplo sobre a re-emergência do gênero - supostamente morto - da epopeia nas literaturas dos países românicos a partir do século 18 até o presente. A hipótese da qual parto é 
de que a suposta morte do gênero tem a ver com sua textualização desperformativa como consequência do pensamento ilustrado, de modo que faz falta, para que se possa efetuar uma espécie de ressurreição do gênero na era moderna, sua re-performativização. Estas textualizações desperformativas e re-performativizações destexualizadoras obedecem a um processo que se chamou performative shift ${ }^{1}$ e que provocou, na era moderna, depois que se tinha efetuado um processo contrário a partir do século 12 até o 17, quando podemos observar a transferência e a incorporação das funções performativas no texto, uma re-transferência das funções da textualidade no performativo. É a partir deste princípio que é preciso conceber a noção de 'auralidade' que proponho aqui: trata-se de um termo procedente dos estudos medievais anglófonos que pretende superar a dicotomia oralidade versus literalidade/letramento ou escrita (o leitor se dá conta de que o termo em inglês, aurality, coincide por homofonia com o termo tradicional da oralidade, orality). Refere-se ao estado in between da recitação oral dirigida para o auditório, ou seja, para a recepção coletiva de um texto fixado de antemão por escrito, mas que conscientemente foi concebido para esta mesma recitação oral. ${ }^{2}$ Assim, minha perspectiva sobre a epopeia já não

\footnotetext{
${ }^{1}$ Segundo a definição do grupo de pesquisa Kulturen des Performativen, na Universidade Libre de Berlim, o performative shift é um processo, "no qual [...] funções determinadas sucessivamente passaram do performativo ao textual ( na Idade Media e nos inícios da época moderna) e ao inverso (na Idade Moderna) [in dessen Verlauf [...] sukzessive bestimmte Funktionen vom Performativen auf Textuelles (im Mittelalter und Früher Neuzeit) übergingen und umgekehrt (in der Moderne)]" (SFB Kulturen des Performativen, 2008).

2 A "Auralidade, em particular, combinou os dois pólos da 'oralidade' e da 'literalidade'/do 'letramento' de uma forma única, cujas implicações não podem ser adequadamente percebidas se a maior parte da energia crítica é dedicada a querer alinhar a auralidade a uma Grande Divisão que se sobrepõe. Auralidade distingue- se de 'oralidade' - i.e., a partir de uma tradição com base no desempenho oral de bardos ou menestréis - por sua dependência de um texto escrito como a fonte da leitura pública. [Aurality, in particular, combined the two poles of 'orality' and 'literacy' in a unique way whose implications cannot properly be perceived if most of the critical energy is devoted to pulling aurality into line with a superimposed Great Divide. Aurality is distinguished from 'orality' - i.e., from a tradition based on the oral performance of bards or minstrels - by its dependence on a written text as the source of the public reading.]" (Coleman, 1996, p.27-28). Além disso - e isso é uma coincidência muito sugestiva - a noção conota a famosa aura no sentido de Walter Benjamin.
} 
coincide com uma perspectiva filológica, centrada na questão do gênero literário, mas com uma perspectiva que define a epopeia como um meio de comunicaçao entre recitador e ouvintes.

Esta perspectiva aural implica que não enfocarei muito nos textos escritos ou impressos das epopeias (textos que chamarei 'textos épicos', em analogia ao termo Dramentext - 'texto dramático' - dos estudos teatrais alemães, que se refere ao texto escrito ou impresso de uma peça teatral), mas naqueles textos mais gerais e plurimediais que em alemão se chamam Aufführungstexte - literalmente 'textos da representação' (FISCHER-LICHTE, 1983). No entanto, este enfoque encerra em si um problema grave com que tiveram que se defrontar, desde sempre, os estudos teatrais: muitas vezes, e mais ainda em contextos históricos, há uma escassez de fontes que tivessem conservado o texto da representação. Às vezes, o único acesso a sua reconstrução é então, paradoxalmente, o acesso por meio do texto escrito, isso é, do texto épico - veremos em seguida que se trata de um problema que surge também n’O Guesa.

\section{A totalidade do argumento de $\mathbf{O}$ Guesa e sua performatividade formal}

Um dos poucos documentos que dá alguma ideia de como imaginar-se a recitação pública desta obra é o prefácio do autor incluído na edição de 1876. Ali podemos ler como não se deve ler - isto é, recitar - a obra:

O Guesa nada tendo do dramático, do lírico ou do épico, mas simplesmente da narrativa, adotei para ele o metro que menos canta, e como se até lhe fosse necessária, a monotonia dos sons de uma só corda; adotei o verso que mais separa-se dos esplendores de luz e de música, mas que pela severidade sua dá ao pensamento maior energia e concisão, deixando o poeta na plenitude intelectual [...] O Guesa [...] fala em voz baixa e, quando muito, grita ou geme, por vezes [...] (Sousândrade 1982:165-166).

No entanto, resulta impossível reconstruir o texto da representação da epopeia únicamente sobre a base desta passagem; só sabemos que Sousândrade refutou o patetismo da recitação dos seus contemporâneos. Por isso, neste caso é preciso - e inevitável 
- analisar também a versão escrita da obra, porque esta talvez contenha alguns indícios das possíveis formas do texto da representação. Falemos então, mesmo que tenha assinalado que não queria enfocar muito nele, do texto épico.

Sabe-se que o conflito central de O Guesa se baseia em uma lenda resumida pelo própio Sousândrade mediante uma larga citação de um texto do viajante francês Ferdinand Denis. Nele se explica o título da obra que ao mesmo tempo é o nome do herói; trata-se da suposta vítima de um ritual dos indígenas muíscas da Colômbia:

A vítima era uma criança arrancada à força da casa dos pais, numa cidade de uma região conhecida pelo nome de SAN JUAN DE LOS LLANOS. Era O GUESA, ou o errante, isto é, a criatura sem asilo; e contudo tratavam dele com grande cuidado no templo do sol, até que chegasse à idade de quinze anos. Este período de quinze anos forma a indicção dos Muíscas. Então levavam O GUESA em procissão pelo SUNA, nome dado à estrada que Bochica havia percorrido na época em que vivia entre os homens, e chegavam à coluna que servia para medir as sombras equinoxiais. OS XEQUES, ou sacerdotes, mascarados à maneira egípcia, representavam o sol, a lua, os símbolos do bem e do mal, os grandes répteis, as águas e as montanhas. Chegando à extremidade do SUNA, a vítima era amarrada a uma pequena coluna e morta a flechadas. Os XEQUES recolhiam seu sangue em vasos sagrados e arrancavam-lhe o coração para oferecê-lo ao sol (apud LOBO, 2005, p.62).

Chama a atenção que o mito principal que sustenta a obra de Sousândrade não é uma lenda originalmente brasileira, mas uma lenda colombiana na qual se manifesta, já no conteúdo, o pan-americanismo do autor. O Guesa começa nos Andes, se invoca inclusive ao rei inca, e depois, pouco a pouco, se aproxima, descendo à Amazônia, do Brasil, percorrendo também todas as demais regiões do continente em uma espécie de odisséia pan-americana que o leva até a Europa e África. É óbvio que Sousândrade trata de moldar um mundo total, primeiro pan-americano e depois inclusive pan-continental, que de certo modo bem corresponde à famosa noção de 'totalidade épica' no sentido de Hegel e Lukács, à qual tantas vezes se recorreu para caracterizar o gênero da epopeia. ${ }^{3}$

\footnotetext{
${ }^{3}$ Niemeyer observa que Sousândrade - diferentemente das foundational fictions do Romantismo latino-americano - não define a identidade, mas que a busca numa errância infinita que por isso ainda não chega à totalidade: "[...] não se
} 
Também o metro fundamental de $\mathrm{O}$ Guesa alude aos moldes épicos clássicos. Com a exceção de dois cantos, Sousândrade escolhe, igual a Camões nos Lusíadas, ao decassílabo heróico, que por sua vez é a adaptação lusitana do endecassílabo italiano das epopeias de Tasso ou de Ariosto. No entanto, Sousândrade formalmente rompe com o paradigma épico tradicional em algumas partes dos cantos II e X, que depois foram chamados (a denominação não é de Sousândrade) Dança de Tatuturema (II) e Inferno de Wall Street $(\mathrm{X})$. Nestas passagens, o autor emprega um molde métrico que desde os estudos dos irmãos Campos foi caracterizado, com razão, como uma adaptação brasileira do limerick anglófono.

Mas é interessante observar como o processo do performative shift, que teve como consequência, em uma primeira fase, a textualização completa da performatividade inerente aos limericks da tradição oral e popular, se reorienta na obra de Sousândrade em uma direção oposta. Para captar o específico desta reorientação da segunda fase do performative shift faz falta, no entanto, enfocar na primeira - e enfocar também nos meios com que se tinha alcançado esta textualização do limerick oral. Referimo-nos aos assim chamados chapbooks, que são a variante inglesa dos occasionelles francesas, ou, também, dos pliegos sueltos espanhóis utilizados para a conservação escrita dos romances castelhanos (CHARTIER, 1997). Todos estes meios, os chapbooks dos limericks incluídos, estão portanto vinculados com o fenômeno da auralidade porque fica prefigurada neles a recitação pública e oral. Apesar de já serem produtos impressos da era de Gutenberg e, por isso, supostamente textos no sentido moderno, sua função ainda se limita, nos séculos 16 e 17, em ser pretextos destinados a realizar-se em atos performativos; são textos que absorveram a performatividade que com o esclarecimento se perde quase completamente.

trata, como nas 'ficções de fundação' do romantismo latino-americano de uma definição (sacrificada) senão da busca de identidade, uma busca que no fim deve ser inacabada. [(..) es geht nicht, wie in den üblichen 'foundational fictions' der lateinamerikanischen Romantik, um die (opferreiche) Setzung, sondern um die Suche nach Identität, eine Suche, die am Ende unvollendet bleiben muß]" (Niemeyer, 2007, p.429). 


\section{Formas da auralidade em Inferno de Wall Street: homofonias, aparição de arautos e manchetes}

Mas em que exatamente consiste, pois, a segunda fase daquele performative shift que se reflete em $\mathrm{O}$ Guesa? Para responder a esta pergunta, vejamos o episódio Inferno de Wall Street. Trata-se de uma passagem bastante complexa e muito comentada em que Sousândrade faz uso de uma técnica de colagem que esconde a trama narrativa. Quase todas as 176 estrofes ou limericks, nas quais se rimam - eis aqui outra manifestação do pan-americanismo de Sousândrade - não somente lexemas portugueses, mas também ingleses e alguns franceses, holandeses e castelhanos, dispõem de didascálias introdutórias, às vezes bastante extensas, postas entre parênteses, ou seja, dispõem de uma espécie de co-texto (no sentido de Ingarden), de caráter quase dramático, em que se especificam os falantes das estrofes respectivas e sua entrada em cena, de modo que se produz uma mistura de vozes tanto polífona como poliglota. Segundo se deduz das primeiras duas estrofes, estamos em Nova Iorque, mais precisamente na Wall Street, cuja bolsa de valores resulta ser o acesso a um inferno moderno:

(O GUESA tendo atravessado as ANTILHAS, crê-se livre dos XÈQUES e penetra em NEW-YORK-STOCK-EXCHANGE; a VOZ, dos desertos):

- Orpheu, Dante, Eneas, ao inferno

Desceram; o Inca ha de subir ...

= Ogni sp'ranza laciate, [sic]

Che entrate ... [sic]

- Swedenborg, ha mundo por vir?

(XÈQUES surgindo risonhos es disfarçados em Railroad-managers, Stockjobbers, Pimbrokers, etc., etc., apreogando:)

- Hárlem! Erie! Central! Pennsylvania!

= Milhão! Cem milhões!! Mil milhões!!!

- Young é Grant! Jackson,

Atkinson!

Vanderbilts, Jay Goulds, anões! (SOUSÂNDRADE, 1982, p.1-2)

\footnotetext{
${ }^{4}$ Os fragmentos de $\mathrm{O}$ Guesa na edição dos irmãos Campos não têm paginação. Por isso, as cifras entre parênteses ao final das citações da epopeia mesma não indicam a página, mas o número da estrofe/do limerick.
} 
Não posso comparar aqui este inferno nova-iorquino de Sousândrade com os textos respectivos de um García Lorca (Poeta en Nueva York) ou de um Cardoza y Aragón (Pequeña sinfonía del Nuevo Mundo); também não há espaço para um estudo infernal comparativo à luz da atual crise financeira; só queria chamar a atenção ao fato de que não é uma mera coincidência que Sousândrade jogue aqui, equiparando os sacrificadores de vítimas humanas com brokers modernos, com a homofonía do lexema xeque com X e cheque com $\mathrm{CH}$ - sacerdote sangrento e cheque de dinheiro - na qual se manifesta, de novo, a auralidade. Seguindo o intertexto dantesco, topamos no inferno sousandradino com numerosas personalidades do mundo político, econômico e social, com várias pessoas semi-famosas da Nova Iorque do século 19 envolvidas em escândalos de diversa índole. Em várias estrofes, o jornalista Sousândrade (que escreveu durante sua estadia em Nova Iorque para o jornal O Novo Mundo) emprega e re-coloca fragmentos tomados de artigos jornalísticos ao mesmo tempo em que recorre a técnicas jornalísticas em geral: isto é, a técnicas especificamente textuais que, por meio do estilo direto, resultam re-traduzidas para a língua falada por meio da entonação e da recitação. ${ }^{5}$ Sousândrade descreveu seu procedimento da maneira seguinte:

[...] o Autor conservou nomes próprios tirados à maior parte dos jornais de New York e sob a impressão que produziam. Ele vai ouvir a voz de cada natureza; e trata o gênio de cada lugar à luz do momento em que por ali passa [...] (SOUSÂNDRADE, 1982, p.168).

Como sugere Santos (1983), alguns dos versos em Inferno de Wall Street podem ser lidos como uma espécie de manchete; sua sintaxe elíptica e o fato de que aparecem nos limericks repórteres como personagens apóiam essa interpretação. Talvez (seria preciso comprovar isso nos arquivos dos diários de Nova Iorque do século 19) Sousândrade inclusive intercale manchetes reais no seu texto -

\footnotetext{
${ }^{5}$ Seja dito de passagem que se comprova a importância da entonação - e com ela também da auralidade - se tomamos em conta as numerosas modificações do texto de edição a edição, que às vezes somente concernem à pontuação; também se observa nos fragmentos anteriores o uso diferenciado dos pontos de exclamação acumulados etc.
} 
por exemplo, nas estrofes seguintes, nas quais cita ou, pelo menos, finge citar os diários The Herald e The Sun, os quais comentam, ao modo de duas personagens falantes e dialogizantes introduzidas pelas didascálias quase teatrais, a visita muito conhecida do Imperador brasileiro Dom Pedro em 1876 aos EUA, por causa da Exposição Mundial de Philadelphia:

([...] HERALD deslealmente desafinando a imperial "ouverture":)

- Agora o Brasil é república;

O Trono No Hevilius caiu ...

But we picked it up!

- Em farrapo

'Bandeira Estrelada' se viu. (SOUSÂNDRADE, 1982, p.44).

E, como réplica, The Sun inverte as relações pan- ou interamericanas, postulando, ironicamente, que Dom Pedro seja nomeado presidente dos EUA:

(THE SUN:)

- Agora a União é Império;

Dom Pedro é o nosso Imperador:

'Nominate him President';

Resident ...

Que povo ame muito a Senhor. (SOUSÂNDRADE, 1982, p.45).

Como anti-monárquico apaixonado, sem dúvida, Sousândrade nos dá uma visão não tão favorável do Imperador; o jornal $O$ Novo Mundo, para o qual escreveu, é outra das muitas vozes que entoam um limerick. Da parte do autor implícito Sousândrade se percebe assim certo tom satírico - e até profético, pois na próxima citação se insinua a derrubada do monarca brasileiro fazendo alusão à queda do filho do rei Baltasar de Babilônia e à Revolução Francesa. A sátira se refere à relação do episódio real (real no seu duplo sentido) da tradução do hino nacional norte-americano ao português feita pelo mesmíssimo Dom Pedro. Esta tradução real foi publicada no jornal The New York Herald, que então era o maior concorrente do The Sun. No limerick 142, há uma encenação performativa da impressão do hino, quando se mencionam, com o lexema inglês silver lusitanizado, os "Sílvios dedos" do tipógrafo que 
prepara o hino real para a impressão, "rutilando ao tipografiar em vernáculo da 'BANDEIRA ESTRELADA'"; e diretamente depois desta representação performativa do textual-tipográfico se escuta "a VOZ", também performativa, do "POETA extático":

(Sílvios dedos rutilando ao tipografiar em vernáculo da 'BANDEIRA ESTRELADA';

POETA extático; a VOZ:)

- Grandes são graças e tesouros

De Baltasar-Imperador!..

$=$ Que treme aí sans-culottes

Quijotes?..

- Manè-Tessèl-Farès, Senhor! (SOUSÂNDRADE, 1982, p.142).

Mas em Inferno de Wall Street ainda há mais provas para documentar essa transferência de técnicas textuais ao performativo; por exemplo, o fato de que o Guesa pratica um gênero tipicamente jornalístico - o 'pessoal', ou seja, o anúncio de contato - que em seguida se recita a si mesmo, em voz alta:

(O GUESA escrevendo personals no HERALD e consultando as SIBILAS de NEW YORK:)

- Young-Lady da Quinta Avenida,

Celestialmente a flirtar

$\mathrm{Na}$ igreja da Graça ...

- Tal caça

Só mata-te almighty dollár (SOUSÂNDRADE, 1982, p.35).

As sibilas nova-iorquinas que se mencionam aqui, seja dito de passagem, são as irmãs e feministas Victoria e Tennesse Claflin, que percorriam, na sua juventude, junto com seu pai, as feiras do país predizendo a fortuna (daí suas capacidades sibilinas ou videntes). Quando adultas fundaram a revista (o sabemos graças ao excelente glossário dos irmãos de Campos) Woodhull and Claflin's Weekly, precursora da imprensa amarela moderna, que se destacou, por exemplo, por revelar o adultério do predicador Henry Ward Beecher, irmão da autora de A Cabana do Pai Tomás, Harriet Beecher Stowe, com a senhora Elizabeth Tilton; são as manchetes deste escândalo às que Sousândrade alude em outra estrofe. 
Mas o exemplo talvez mais contundente da contra-direccionalidade do performative shift da era moderna frente à era pre- moderna é outro, pois também o procedimento alegórico que textualizara as antigas alegorias em forma de livros e emblemas sofre um processo de re-performativização e auralização: na medida em que Sousândrade personifica o já mencionado jornal The New York Herald, que depois intervém como personagem, assistimos a uma espécie de ressurreição das alegorias-corpos e a uma re-polarização do performative shift que até o Esclarecimento sempre se dirigia para o textual. Como se demonstrou em trabalhos dedicados ao nascimento da esfera pública e da imprensa no âmbito peninsular sobre a base das tertúlias como forma de sociabilidade típica do mundo hispano e lusitano, não é pouco frequente que os novos diários e revistas iluministas de então tratassem de recompensar a perda do ambiente social e performativo das tertúlias frente ao mundo textual e anonimizado da imprensa mediante estratégias que fingiam a recitação pública dos textos jornalísticos através dos personagens alegóricos que se manifestam nos títulos dos diários (Gelz 2006). Como alegorias, se escrevem, sem dúvida, com maiúsculas: El Pensador, El Correspondal del Censor ou inclusive El Murmurador Imparcial, etc. Certamente, os há também no âmbito anglófono onde o título The New York Herald remete a uma prévia textualização emblemática do arauto medieval, que no âmbito lusófono aparece em jornais chamados $\mathrm{O}$ Arauto, $\mathrm{O}$ Arauto das Letras, etc. A ressurreição destes personagens alegóricos textualizados pelo nascimento da imprensa durante o Esclarecimento e sua reconversão em personagens performativos, como demonstra o exemplo do Herald personificado em Sousândrade, são sintomas inequívocos de que, a partir do século 19, o performative shift se reorienta por fim para a performativização do textual.

Além disso, a estratégia da alegorização do jornal se correlaciona com o mundo moderno real da época de Sousândrade, na qual havia garotos vendedores de jornais proclamando ou gritando as manchetes, ou pessoas que os levavam sobre seus corpos em forma de cartazes - em ambos casos, são arautos modernos. Lembremos que na Londres ou Nova Iorque do século 19 ainda havia muita gente analfabeta que dependia de alguém que lhes lesse as 
notícias dos jornais (LYONS, 1997, p.399). Uma função muito parecida assumem pois os arautos modernos que emblematicamente encarnam a auralidade da estratégia textual das manchetes. $\mathrm{O}$ arauto supostamente morto da era pre-moderna, cuja performatividade definitivamente se tinha transladado ao texto durante o Esclarecimento e suas campanhas de alfabetização, volta no século 19 como pregoeiro de manchetes, como representante da imprensa e dos meios massivos. Seria errôneo considerá-los a estes novos arautos como meros sobreviventes de uma práxis performativa pré-moderna cujas palavras só satisfazem aos que não sabem ler, pois, em uma época em que ainda não existiam nem o rádio nem a televisão, suas palavras entoadas também satisfazem àqueles que sem saber ler - mas que preferem escutar, fato pelo qual se produz um fenômeno que eu gostaria de chamar 'excedente aural'. O textual - a compressão jornalística da mensagem do arauto originário por meio da imprensa em forma da sintaxe característica das manchetes - se infiltrou nas atuações performativas dos arautos modernos que, ao proclamar estas mesmas manchetes, põem em cena uma sintaxe que não é de origem oral, mas escrita, e que não obstante se recita auralmente. Fica claro, portanto, que não se trata aqui de recuperar uma forma perdida, mítica ou primitiva da oralidade, ou seja, nenhuma oralidade primária no sentido de Ong (1988); também não tem a ver o fenômeno com a oralidade residual, mas o cabal desta constelação é a posta em cena da auralidade que suplementa o texto escrito por meio de elementos orais, assim como suplementa o texto falado através de elementos escritos.

\section{Conclusões}

Se assistimos, neste momento, não somente à ressurreição das alegorias textualizadas, mas - talvez - também à ressurreição do gênero da epopeia em geral, esta ressurreição depende necessariamente da auralidade. Só a auralidade permite reanimar o gênero da epopeia, literalmente morto sobre o papel, colocando-o em cena como um dispositivo performativo que inclui a possibilidade de uma recepção coletiva. É por isso que leio - que interpreto - 
as palavras de Sousândrade citadas já no início: "O Guesa [...] fala em voz baixa e, quando muito, grita ou geme, por vezes [...]" (SOUSÂNDRADE, 1982, p.165-166). Esta citação resulta ser por sua vez uma auto-citação tomada de um dos limericks de Inferno de Wall Street:

Pois há, entre o Harold e o Guesa,

Diferença grande, e qual é,

Que um tem alta voz

E o pé bot,

'Voz baixa' o outro, e firme o pé (SOUSÂNDRADE, 1982, p.79).

Eis aqui outra alusão à auralidade inerente à epopeia, pois somente na recitação oral ou aural se realiza a homofonia - e com ela a polissemia - do significado Harold/Herald. Nesta estrofe, Sousândrade não somente se distância frente a outras epopeias contemporâneas e se refere a Childe Harold - com A e O, tal como está escrito aqui -, ou seja, ao herói do poema épico de Lord Byron, Childe Harold's Pilgrimage, mas também se aparta, por meio da homofonia, das epopeias tradicionais de caráter oral representadas pelo emblemático arauto medieval, ou seja, o herald escrito com E e A. Se parece que em tempos da oralidade primária faz falta falar em voz alta, declamar e escandir bem, já não existe a mesma necessidade em constelações aurais: se os receptores sabem ler e escrever, podendo reler o que talvez no ato performativo não entenderam, a recitação também pode efetuar-se "em voz baixa”, abrindo-se a uma multitude de matizes que produzem outro tipo de experiência receptora. Seria, pois, um novo modo de coexistência da voz com a escrita, uma espécie de 'obra total' na qual a 'totalidade épica’ já não se restringe à estrutura interna da epopeia, ou seja, a aspectos que concernem ao conteúdo como o pan-americanismo do autor, ou à forma textual na qual se destaca o que Hegel chamou de "coordenação" (Reihung). Além disso, a 'totalidade épica' abrange também o texto da representação épica na sua realização performativa. Talvez inclusive se possa dizer que, a partir do pan-americanismo situado no nível da trama de $\mathrm{O}$ Guesa, haverá algum acesso a um pan-medialismo formal que libera a epopeia moderna de seu invólucro mono-medial que é o texto épico escrito. 


\section{Referências}

BEISSINGER, Margaret; TYLUS, Jane; WOFFORD, Susanne (eds.). Epic Traditions in the Contemporary World: The Poetics of Community. Berkeley: University of California Press, 1999.

CAMPOS, Augusto de; CAMPOS, Haroldo de (eds.). ReVisão de Sousândrade. Textos críticos, antologia, glossário, biobibliografia. Rio de Janeiro: Nova Fronteira, 1982.

CHARTIER, Roger. Lectures et lecteurs 'populaires' de la Renaissance à l'âge classique. In: CAVALLO, Guglielmo; BONFIL, Robert (eds.). Histoire de la lecture dans le monde occidental. Paris: Éd. du Seuil, 1997. p. 315-330.

COLEMAN, Joyce. Public Reading and the Reading Public in Late Medieval England and France. Cambridge: Cambridge University Press, 1996.

DUARTE, Sebastião Moreira. Epica americana: "O Guesa," de Sousândrade e o "Canto general" de Pablo Neruda. Dissertação, Urbana (Illinois), 1993.

FISCHER-LICHTE, Erika. Semiotik des Theaters. v. 3: "Die Aufführung als Text”. Tübingen: Gunter Narr, 1983.

GELZ, Andreas. Tertulia. Literatur und Gesellschaft im Spanien des 18. und 19. Jahrhunderts. Frankfurt am Main: Vervuert, 2006.

LABARTHE, Judith (ed.). Formes modernes de la poésie épique: nouvelles approches. Bruxelas: Peter Lang, 2004.

LOBO, Luiza. Epica e modernidade em Sousândrade. Rio de Janeiro: Presença, 1986.

LYONS, Martyn. Les nouveaux lecteurs aux XIXe siècle. In: CAVALLO, Guglielmo; BONFIL, Robert (eds.). Histoire de la lecture dans le monde occidental. Paris: Éd. du Seuil, 1997. p. 365-400.

NEIVA, Saulo (ed.). Désirs et débris d'épopée au XXe siècle. Berna: Lang, 2009a.

NEIVA, Saulo. Avatares da epopeia na poesia brasileira do final do século XX. Recife: Fundação Joaquim Nabuco/Ed. Massangana, 2009b. 
NEIVA, Saulo (ed.). Déclin et confins de l'épopée au XIXe siècle. Tübingen: Narr, 2008.

NIEMEYER, Katharina. Ein Brasilianer in New York. Raum und Sprache in Inferno de Wall Street von Sousândrade. Romanistisches Jahrbuch, v. 57, p. 423-441, 2007.

OBERHELMAN, Steven M.; KELLY, Van; GOLSAN, Richard J. (eds.). Epic and Epoch: Essays on the Interpretation and History of a Genre. Lubbock: Texas Tech University Press, 1994.

ONG, Walter J. Orality and Literacy: The Technologizing of the Word. 2. ed., Londres e Nova Iorque: Routledge, 1988.

SANTOS, Mirian dos. A modernidade semiótica de Sousândrade. Traços intersemiôticos na sintaxe do Guesa errante. Dissertação, São Paulo: Universidade Católica de São Paulo, 1983.

SFB KULTUREN DES PERFORMATIVEN. Gesamtkonzept, 2008. Disponível em: < www.sfb- performativ.de/seiten/frame_gesa.html> . Acesso em: 14 jul. 2011.

SILVA, Anazildo V. da; RAMALHO, Christina. História da epopeia brasileira. Rio de Janeiro: Editora Garamond, 2007.

SOUSÂNDRADE, Joaquim. O Guesa. In: CAMPOS, Augusto de; CAMPOS, Haroldo de (eds.). ReVisão de Sousândrade. Textos críticos, antologia, glossário, biobibliografia. 2.ed. Rio de Janeiro: Nova Fronteira, 1982.

WILLIAMS, Frederick G. Sousândrade: vida e obra. São Luís: SIOGE, 1976.

Recebido em: 5/9/2011

Aceito em: 7/4/2012 